\title{
$\alpha$-BUNGAROTOXIN LABELING AND ACETYLCHOLINESTERASE LOCALIZATION AT THE MAUTHNER FIBER GIANT SYNAPSE IN THE HATCHETFISH ${ }^{1}$
}

\author{
JOHN WEST DAY, DAVID H. HALL, LINDA M. HALL, AND MICHAEL V. L. BENNETT ${ }^{2}$ \\ Division of Cellular Neurobiology, Department of Neuroscience, Albert Einstein College of Medicine, Bronx, New York 10461
}

Received October 26, 1981; Revised September 29, 1982; Accepted, September 30, 1982

\begin{abstract}
Autoradiographic and histochemical techniques have been used to characterize further the pharmacology of transmission at the Mauthner fiber giant synapse of the South American hatchetfish. $\left[{ }^{125} \mathrm{I}\right] \alpha$-Bungarotoxin was applied to hatchetfish medullae and a standard autoradiographic procedure was carried out on 3- to 4- $\mu \mathrm{m}$ sections of glutaraldehyde-fixed tissue. All Mauthner fiber giant synapses, as identified by light microscopic criteria, had closely associated silver grains. Labeling was blocked by $d$-tubocurarine. Glutaraldehyde-fixed slices of hatchetfish medulla were stained histochemically for acetylcholinesterase; all giant synapses that could be identified in the light microscope showed heavy deposits of reaction product. Staining was blocked by diisopropylfluorophosphate, which inhibits both pseudocholinesterase and acetylcholinesterase, but was not blocked by tetraisopropylpyrophosphoramide, a specific pseudocholinesterase inhibitor. This evidence strongly supports the suggestion that the Mauthner fiber giant synapse is nicotinic cholinergic.
\end{abstract}

The Mauthner fiber system of teleosts and amphibia has been studied extensively by anatomical, physiological, and behavioral methods (Faber and Korn, 1978). In the medulla of the South American hatchetfish the Mauthner fiber forms large chemical synapses on a number of large myelinated axons termed giant fibers (Model et al., 1975). These axons mediate excitation of pectoral fin motoneurons bilaterally (Auerbach and Bennett, 1969) and in this fish bilateral pectoral fin adduction is an important component of the Mauthner fiber-mediated escape reflex. Physiological studies of the Mauthner fiber giant synapse demonstrated that repetitive stimulation causes a rapid rundown of postsynaptic potential (PSP) amplitude that is accompanied by depletion of presynaptic vesicles (Auerbach and Bennett, 1969; Highstein and Bennett, 1975; Model et al., 1975). The time course of recovery of PSP amplitude suggests that a pool of transmitter immediately available for release is restored rapidly and that the time required for filling a vesicle is

' This work was supported in part by National Science Foundation Grant BNS 79-29435 and by the Council for Tobaceo Research U. S. A., Inc. Grant 1126 to L. M. H. and National Institutes of Health Grants NS-12627, NS-07512, and HD-04248. J. W. D. was supported by a National Research Service Award. We wish to thank T. SchmidtGlenewinkel and T. R. Venkatesh for preparing the iodinated toxin and W. D. Huse and P. G. Model for helpful discussions and suggestions.

${ }^{2}$ To whom correspondence should be addressed. less than $1 \mathrm{sec}$ (Highstein and Bennett, 1975). Pharmacological intervention in this process requires a knowledge of the transmitter substance. In voltage clamp studies the postsynaptic current decays in two phases (Huse and Bennett, 1981) as do averaged miniature PSPs (Day et al., 1981). Analysis of the decay mechanisms should be facilitated by identification of the transmitter and of factors leading to its removal from the synaptic cleft.

Preliminary data reported earlier suggested that transmission at the Mauthner fiber giant synapse is cholinergic (Spira et al., 1970). $d$-Tubocurarine $(0.1 \mathrm{~mm}$ ) topically applied in the fourth ventricle reversibly blocks the PSP, and topical acetylcholine also reversibly blocks the PSP with little prior depolarization. We supposed that desensitization proceeds rapidly enough to prevent a large depolarization. There are few data from other animals. Histochemical studies by both Lewis (1961), working on Xenopus tadpoles, and Pfister et al. (1973), working on rainbow trout, showed that the Mauthner cell soma stains for acetylcholinesterase; neither of these studies showed stain at any Mauthner fiber synapses; thus nothing could be directly stated about the Mauthner fiber transmitter in these two species.

To obtain further evidence for cholinergic transmission, we used $\alpha$-bungarotoxin $(\alpha-\mathrm{BGT})$, a high affinity and slowly reversible ligand for acetylcholine receptor molecules (Chang and Lee, 1963). Binding was detected autoradiographically with ${ }^{125}$ T-labeled toxin. We also 
demonstrated acetylcholinesterase at the synapses by the histochemical technique of Lewis and Shute (1966). A preliminary report has appeared (Hall et al., 1981).

\section{Materials and Methods}

The hatchetfish used in these experiments were obtained through tropical fish dealers and were maintained in laboratory aquaria. During experiments they were placed in a standard fish holder and their gills were perfused with teleost saline composed of $169 \mathrm{~mm} \mathrm{NaCl}$, $5 \mathrm{~mm} \mathrm{KCl}, 3 \mathrm{~mm} \mathrm{CaCl}_{2}, 1.5 \mathrm{~mm} \mathrm{MgCl}_{2}$, and $2 \mathrm{~mm}$ HEPES buffer at pH 7.4 (Auerbach and Bennett, 1969).

\section{1. $\alpha$-Bungarotoxin autoradiography}

Binding assays indicated that homogenates of hatchetfish medullae bound $\alpha$-BGT and that this binding was blocked by $d$-tubocurarine but was unchanged by formalin fixation of the tissue before homogenization (Hall et al., 1981). For the autoradiographic studies presented here, $\left[{ }^{125} \mathrm{I}\right] \alpha$-BGT was injected into the fourth ventricle of living fish which were subsequently immersed in fixative. This procedure gave us good morphology and labeling and low autoradiographic background; clear labeling could also be obtained with injection subependymally into the medullae of living fish or by incubation of formalin-fixed medullae in $\left[{ }^{125} \mathrm{I}\right] \alpha$-BGT solution.

$\alpha$-BGT (Miami Serpentarium) was radiolabeled using the chloramine T method (Schmidt-Nielsen et al., 1977), and the fraction containing monoiodo- and unlabeled $\alpha$ bungarotoxin was separated from other reaction products as described by Blanchard et al. (1979). Four different preparations of iodinated toxin were used, having initial specific activities which ranged from 48 to $800 \mathrm{Ci} /$ mmol, and were used in the concentration range of 50 to 700 nM; no differences, aside from the length of time needed to adequately expose the emulsion, were appreciable in the four batches. The incubation solution used in autoradiographic studies was composed of $\left[{ }^{125} \mathrm{I}\right] \alpha-\mathrm{BGT}, 0.07$ $\mathrm{mg} / \mathrm{ml}$ of cytochrome $c, 0.1 \mathrm{mg} / \mathrm{ml}$ of bovine serum albumin, and $20 \mathrm{mg} / \mathrm{ml}$ of fast green dye in teleost saline with 2 mM HEPES buffer, $\mathrm{pH}$ 7.4; in control experiments the solution also contained $0.6 \mathrm{~mm} d$-tubocurarine. The bovine serum albumin and cytochrome $c$ were added to reduce adsorption of $\alpha$-BGT onto the wall of the glass pipette used for the injection. Fast green dye was an aid to visualization of solution during the injection and was shown in a binding assay not to interfere with $\alpha$-BGT binding.

Glass pipettes used for the injection were filled with mineral oil, attached via polyethylene tubing to a micrometer-driven syringe, and filled just before they were used. They were filled by first drawing in through the tip (approximately $5 \mu \mathrm{m}$ outside diameter) a solution of teleost saline containing $1 \mathrm{mg} / \mathrm{ml}$ of bovine serum albumin to coat the walls of the pipette with protein; that solution was ejected and approximatcly $5 \mu \mathrm{l}$ of the $\left[{ }^{125} \mathrm{I}\right] \alpha^{-}$ BGT solution to be injected were then drawn into the pipette.

A fish was placed in the holding apparatus and, after removing the portion of the skull covering the medulla, the meningeal covering of the fourth ventricle was re- moved. 'The $\left[{ }^{125} \mathrm{I}\right] \alpha$-BG' $\mathrm{I}$ ' solution was injected into the ventricle for a period of approximately $30 \mathrm{~min}$; in control experiments approximately $10 \mu \mathrm{l}$ of $0.6 \mathrm{~mm} d$-tubocurarine in teleost saline were applied to the fourth ventricle for $20 \mathrm{~min}$ before the incubation solution $\left(\left[{ }^{125} \mathrm{I}\right] \alpha\right.$-BGT plus $d$-tubocurarine) was injected. After the entire volume of solution had been applied, the fish remained in the holder for an additional $30 \mathrm{~min}$ to ensure adequate access of the toxin to the synapses; the fish continued to move and respire throughout this period. The fish then was removed from the holder, placed in a beaker, and washed for 30 to $90 \mathrm{~min}$ in three changes of saline at $4^{\circ} \mathrm{C}$ (alternately with and without $0.1 \mathrm{mg} / \mathrm{ml}$ of bovine serum albumin); in control experiments all washing solutions contained $0.6 \mathrm{~mm} d$-tubocurarine. A pipette was used to direct saline into the exposed cranial cavity to ensure adequate washing. Following the washes, the entire fish was fixed topically for $16 \mathrm{hr}$ at $4^{\circ} \mathrm{C}$ in a solution containing $1 \%$ acrolein, $3 \%$ glutaraldehyde, $2 \%$ formalin, and $2.5 \%$ dimethyl sulfoxide in $0.1 \mathrm{M}$ sodium cacodylate buffer at pH 7.4 (Model et al., 1975; Kalt and Tandler, 1971).

Following fixation the medullae were removed, washed in $0.1 \mathrm{M}$ cacodylate buffer at $\mathrm{pH} 7.4$, and fixed in $0.2 \%$ $\mathrm{OsO}_{4}$ in cacodylate buffer $(\mathrm{pH} 7.4)$ for $16 \mathrm{hr}$. Some osmium fixation was necessary to preserve myelin structure, but osmication with the 1 to $2 \% \mathrm{OsO}_{4}$, which is more usual for electron microscopy caused excessive light scattering from the myelin, obscuring silver grains in darkfield illumination. The tissue was dehydrated and embedded in Epon, and 3- to 4- $\mu \mathrm{m}$ coronal sections were cut through the medulla. Serial sections were collected on clean glass slides and coated with carbon $(5 \mathrm{~nm})$ to minimize contact of osmicated sections with emulsion and to provide a more uniform surface for emulsion application (Salpeter and Bachman, 1972).

Two different autoradiographic emulsions were used in these experiments, Kodak NTB2 and Ilford L4. The NTB2 emulsion was diluted 1:1 with distilled water, and the Ilford L4 emulsion was diluted 1:2 with distilled water. Slides were hand-dipped in the diluted emulsion at $35^{\circ} \mathrm{C}$, allowed to dry in a vertical position, and stored in light-tight boxes with dessicant at $4^{\circ} \mathrm{C}$. Typically, about 2 weeks elapsed between the application of the $\alpha$ BGT and the coating of the slides with emulsion. After exposures of from 2 weeks to 2 months, the slides were developed; the NTB2 slides were developed in Dektol (1:2 water), and the Ilford L4 slides were developed in D19. Test slides exposed to light before developing showed that the emulsion formed an even layer across the entire slide.

\section{Acetylcholinesterase histochemistry}

A Karnovsky and Roots (1964) AChE stain of 500- $\mu \mathrm{m}$ formalin-fixed slices of hatchetfish medullae produced staining of Mauthner fiber giant synapses that was only visible in dark-field microscopy. The method of Lewis and Shute (1966) produced more obvious staining, and these are the experiments reported here.

After removal of the skull and meninges covering the fourth ventricle, the fish were fixed topically at $4^{\circ} \mathrm{C}$ by immersion in Kalt and 'T'andler's (1971) fixative for 16 
hr. The medullae then were removed and a 500- to $800-$ $\mu \mathrm{m}$ coronal section through the open portion of the fourth ventricle of each was cut with a razor blade. This slice of tissue was washed for $24 \mathrm{hr}$ in $0.1 \mathrm{M}$ sodium cacodylate, $\mathrm{pH} 7.0$, at $4^{\circ} \mathrm{C}$.

The slices were incubated for $24 \mathrm{hr}$ at room temperature in a solution of: $13 \mathrm{~mm}$ acetylthiocholine iodide, 18 $\mathrm{mm}$ cupric sulfate, $33 \mathrm{~mm}$ glycine, and $25 \mathrm{~mm}$ sodium succinate, pH 5.3 (Lewis and Shute, 1966). In control experiments the slices were preincubated for $8 \mathrm{hr}$ at room temperature in $0.1 \mathrm{M}$ sodium cacodylate, $\mathrm{pH} 6.5$, which included either $0.1 \mathrm{~mm}$ iso-OMPA (tetraisopropylpyrophosphoramide, Sigma Chemical Co.; a specific irreversible pseudocholinesterase inhibitor) or $0.1 \mathrm{~mm}$ DFP (diisopropylfluorophosphate; Sigma; at this concentration, an irreversible blocker of both pseudocholinesterase and true acetylcholinesterase) (Silver, 1974). The slices then were washed for $24 \mathrm{hr}$ in succinate-buffered sodium sulfate $(67 \mathrm{~mm}$ sodium sulfate, $50 \mathrm{~mm}$ succinic acid, $2 \mathrm{~mm}$ calcium acetate, $\mathrm{pH} 5.3$ ) and were placed for $5 \mathrm{hr}$ at room temperature in a bath containing $1 \%$ sodium sulfide (in the same succinate-buffered sodium sulfate solution, $\mathrm{pH}$ 5.3) which had been freshly made and filtered. The tissue then was rewashed in the succinate-buffered sodium sulfate solution (pH 5.3) for $16 \mathrm{hr}$ and $0.1 \mathrm{M}$ sodium cacodylate ( $\mathrm{pH} 7.4$ ) for $6 \mathrm{hr}$ before being postfixed in $0.2 \%$ osmium tetroxide in $0.1 \mathrm{M}$ sodium cacodylate $(\mathrm{pH}$ 7.4) for $16 \mathrm{hr}$, dehydrated, embedded in Epon, and sectioned at 3 to $4 \mu \mathrm{m}$.

\section{Results}

Figure $1 A$ diagrams the normal relationship of a giant fiber to the two Mauthner fibers in the hatchetfish medulla. There are two to six giant fibers on each side; each arises from a cell body in the lateral wall of the fourth ventricle. Its axon crosses dorsal (or occasionally ventral) to the near Mauthner fiber (whose cell body is located contralaterally) and forms a single synapse with it, the cross-process synapse (Auerbach and Bennett, 1969). The giant fiber then crosses the midline, courses ventrally, and bifurcates, sending branches rostrally and caudally along the other Mauthner fiber with which it forms several synapses, the ipsilateral synapses. Obvious interruptions in the myelin coats of the two fibers are close to the site of each synapse as has been shown by electron microscopic examination of such regions (Model et al., 1975). The synaptic sites thus are readily recognized by light microscopic examination of serial sections (Fig. $1 B$ ).

\section{1. $\alpha$-Bungarotoxin autoradiography}

Synapses from a fish treated with $\left[{ }^{125} \mathrm{I}\right] \alpha-\mathrm{BGT}$ are shown in Figure 2. In Figure $2 A$ most of the silver grains evident in a dark-field/bright-field double exposure lie in a linear region over the ipsilateral synapse. A more frequent observation, especially after long exposure times (Fig. $2 B$ ), is that the synapses are marked by more diffuse accumulations of silver grains independent of which emulsion, NTB2 or Ilford L4, was used. Frequently, a process emanating from a Mauthner fiber projects rostrally or caudally before forming synapses with a giant fiber (Fig. 3, $A$ to $G$ ); in these instances the interruptions in the myelin of the two fibers are in neighboring thick sections. Thin sections through giant synapses reveal that they usually are 5 to $10 \mu \mathrm{m}$ in diameter; thus they normally extend into adjacent thick sections. Consequently, silver grains over a single synapse are found in several adjacent sections (Fig. $3, B$ to $E$ ).

Sections were obtained from nine fish in all whose fourth ventricles were perfused with $\left[{ }^{125} \mathrm{I}\right] \alpha-\mathrm{BGT}$. All experimental fish gave evidence of binding of $\alpha$-BGT to the Mauthner fiber giant synapses; all 135 of the giant synapses identified in the autoradiographic sections showed very strong labeling (Table I).

In four control fish that were pretreated with $d$-tubocurarine and incubated with a combination of $d$-tubocurarine and $\left[{ }^{125} \mathrm{I}\right] \alpha-\mathrm{BGT}$, none of the 45 identified giant synapses showed any definite specific autoradiographic labeling (Table I, Fig. $3 H$ ).

\section{Acetylcholinesterase histochemistry}

Two adjacent sections from a medulla stained for acetylcholinesterase are shown in Figure 4. A presynaptic process from the right Mauthner fiber forms both a crossprocess synapse with one giant fiber and an ipsilateral synapse with another. The left Mauthner fiber forms an ipsilateral synapse with a third giant fiber. All of these synapses show much more reaction product over the synaptic cleft than is seen in the surrounding tissue. In the control experiments in which iso-OMPA was present to block pseudocholinesterase, there seemed to be a diminished amount of background staining and an unchanged amount of stain at the Mauthner fiber giant synapse. In the control experiments in which the medullae were pretreated with DFP, very few stain crystals were seen at all, and none were seen at the identified giant synapses (Fig. $1 B$ ). The crystal size of the copper sulfide is large compared to that in the preparations of Lewis and Shute (1966); this difference may be due to the much longer time that the hatchetfish slices were incubated in the acetylthiocholine solution.

A total of 15 fish were prepared for AChE staining; 10 were pretreated with saline without any cholinesterase blockers, 2 were pretreated with the pseudocholinesterase blocker iso-OMPA, and 3 were pretreated with DFP, which blocks both pseudocholinesterase and true acetylcholinesterase. All medullae pretreated with saline alone or saline with iso-OMPA showed definite deposition of reaction product at all identified Mauthner fiber giant synapses (Table II). In all medullae that had been pretreated with DFP, no identified Mauthner fiber synapses showed any stain at all (Fig. $1 B$, Table II).

\section{Discussion}

The $\left[{ }^{125} \mathrm{I}\right] \alpha$-BGT autoradiographic data presented here comprise the best evidence to date that the hatchetfish Mauthner fiber is nicotinic cholinergic. The Mauthner fiber giant synapses bind $\alpha-\mathrm{BGT}$, and the binding is eliminated by the prior application of $d$-tubocurarine. The incubation time, toxin concentration, and temperature used to produce significant labeling of these synapses were similar to those used to saturate receptors at the 

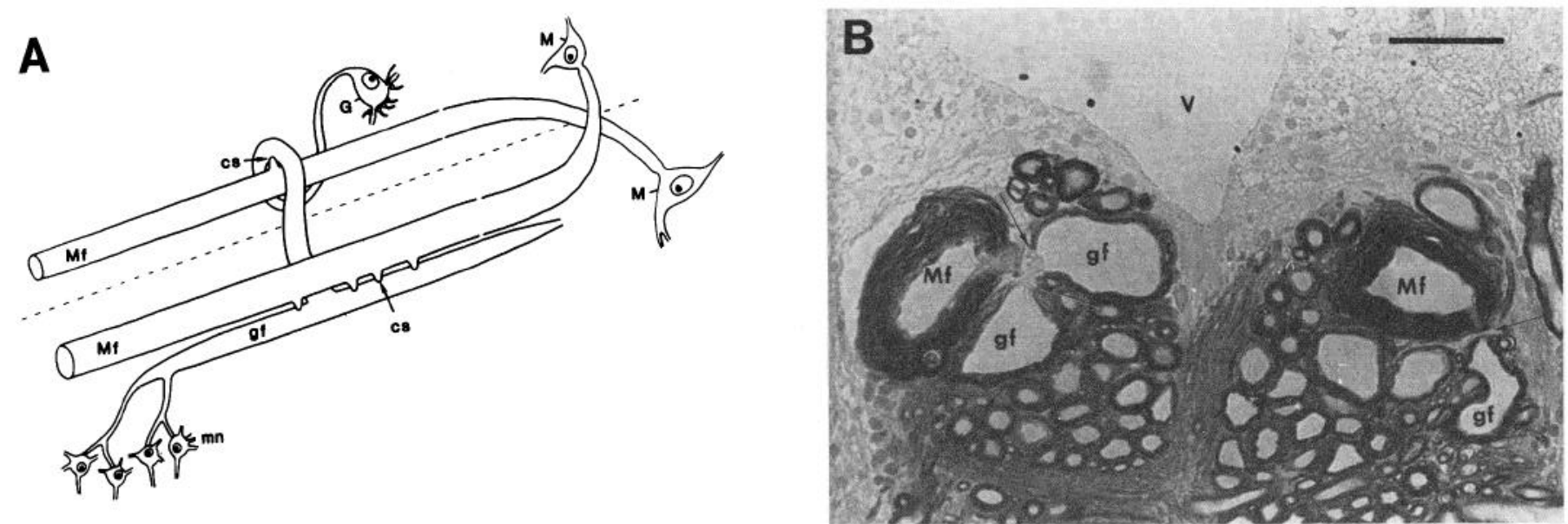

Figure 1. Hatchetfish Mauthner fiber-giant fiber system. A, Diagram of the Mauthner fiber-giant fiber relationships. Each giant fiber ( $g f)$ arises from its cell body $(G)$ in the lateral wall of the fourth ventricle. It passes dorsal to the nearer Mauthner fiber $(M f)$ with which it forms a single chemical synapse $(c s)$, the "cross-process" synapse. The giant fiber then crosses the midline and bifurcates to send branches rostrally and caudally along the other Mauthner fiber with which it forms several chemical synapses, the "ipsilateral" synapses. $M$, Mauthner cell body. $B$, Light micrograph of a coronal section through the medulla of a hatchetfish which had been treated with DFP before being stained for acetylcholinesterase. This section illustrates normal morphology as well as abolition of acetylcholinesterase staining by DFP. The interruptions in the myelin of both Mauthner fibers and three giant fibers (arrows) are indicative of synapses forming between them. The left Mauthner fiber forms a crossprocess synapse with the more dorsal giant fiber and an ipsilateral synapse with the more ventral fiber. The right Mauthner fiber forms an ipsilateral synapse onto a third giant fiber in an adjacent section. Some copper sulfide crystals from the acetylcholinesterase stain are visible near the ependymal surface of the fourth ventricle $(V)$. Abbreviations are the same as in $A$. Scale bar, $50 \mu \mathrm{m}$.
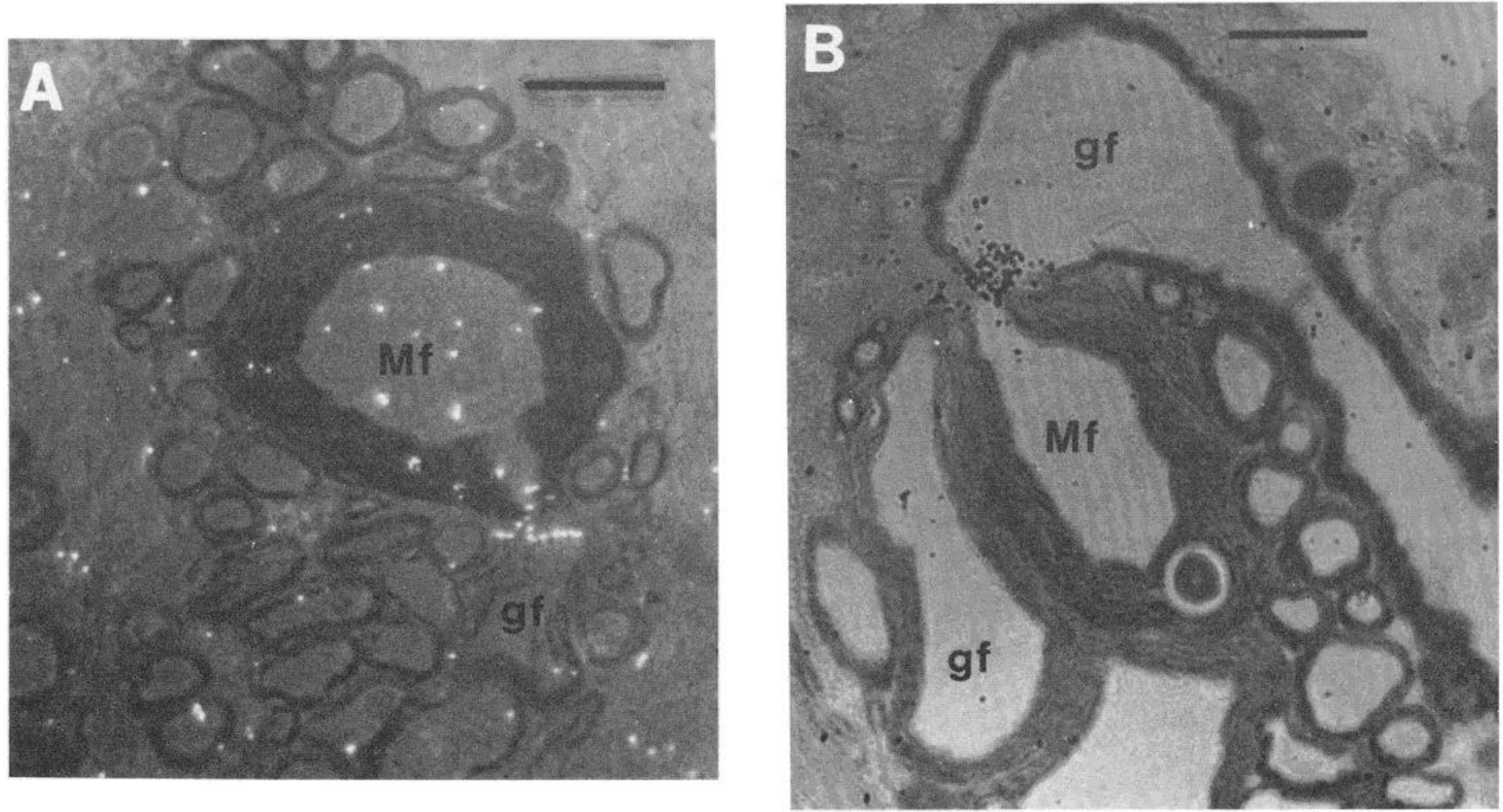

Figure 2. NTB2 autoradiographs of $\left[{ }^{125} \mathrm{I}\right] \alpha$-BGT-treated hatchetfish. $A$, An ipsilateral synapse after a 16-day exposure of the emulsion; the grains form a line over what is presumably the intersynaptic cleft. $B$, A cross-process synapse from the same fish after a 38-day exposure of the emulsion. Grains are clustered over the synapse, a more frequent observation than the linear arrangement in $A$. The toxin in the incubation solution had a specific activity of $62.8 \mathrm{Ci} / \mathrm{mmol}$ and a concentration of $595 \mathrm{~nm}$. Abbreviations are the same as in Figure $1 A$. Scale bars, $20 \mu \mathrm{m}$. 

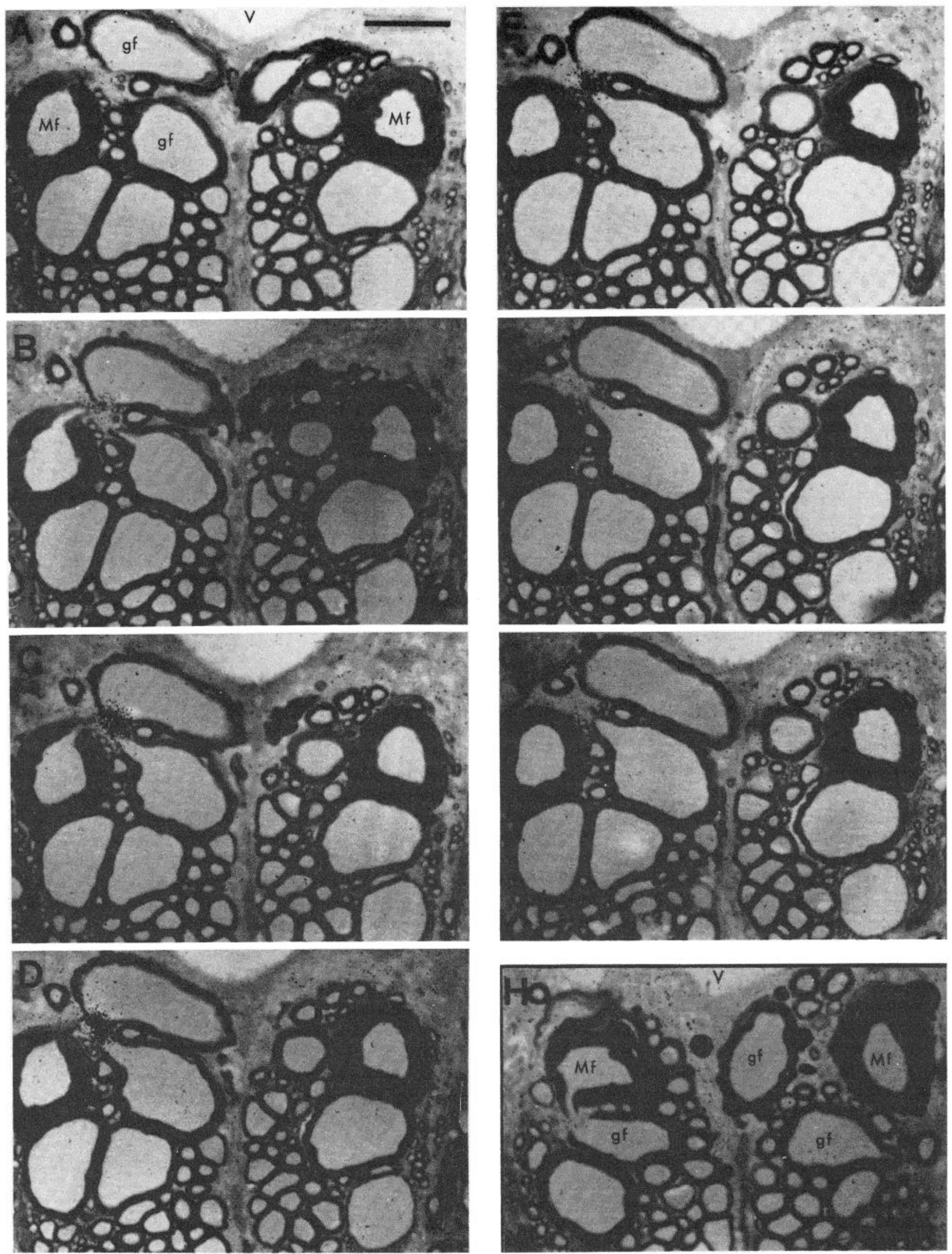

Figure 3. Ilford L4 autoradiography of $\left[{ }^{125} \mathrm{I}\right] \alpha$-BGT-treated hatchetfish. $A$ to $G$, Seven sequential sections through the medulla ( $A$ most rostral) of an $\left[{ }^{125} \mathrm{I}\right] \alpha$-BGT-treated fish show two well labeled giant synapses of the left Mauthner fiber; that with the more dorsal fiber is a cross-process synapse and that with the more ventral is an ipsilateral synapse. The interruptions in the myelin coats of the pre- and postsynaptic fibers are not evident in the same section. Processes from the Mauthner fiber can be followed to the interruption in the giant fiber myelin. $H$, A section from a $d$-tubocurarine control experiment. The synapse formed by the left Mauthner fiber and the giant fiber dorsal to it shows what might be a few specific grains. The number of grains at this synapse was greater than that seen at most control synapses and was still much less than the number seen at synapses when $d$ tubocurarine was not present. In each case (sections $A$ to $G$ and section $H$ ) the $\alpha$-BGT in the incubation solution had a specific activity of $400 \mathrm{Ci} / \mathrm{mmol}$ and a concentration of $108 \mathrm{nM}$; the autoradiographs were all exposed for 32 days before being developed. Abbreviations are the same as in Figure 1. Scale bar, $50 \mu \mathrm{m}$. 
frog neuromuscular junction (Matthews-Bellinger and Salpeter, 1978). While we have not shown that the acetylcholine receptors beome saturated in this time, clearly the ventricular ependyma offers little obstacle to diffusion of even large molecules of this size.

TABLE I

$\alpha$-Bungarotoxin autoradiography

\begin{tabular}{llccl}
\hline Emulsion & Pretreatment & $\begin{array}{c}\text { No. of } \\
\text { Fish }\end{array}$ & $\begin{array}{c}\text { No. of } \\
\text { Synapses }\end{array}$ & Synaptic Label \\
\hline NTB2 & None & 3 & 57 & Very heavy \\
Ilford L4 & None & 6 & 78 & Very heavy \\
Ilford L4 & $d$-tubocurarine & 4 & 45 & None to very light \\
\hline
\end{tabular}

While the $\alpha$-BGT binding sites in the autoradiographic results clearly are restricted to the region of giant synapses in the hatchetfish (Fig. 3, $A$ to $G$ ), of possible concern is the observation that most synapses show clusters of grains (Fig. $2 B$ ) rather than the discrete lines

TABLE II

Acetylcholinesterase histochemistry

\begin{tabular}{lccl}
\hline Pretreatment & $\begin{array}{c}\text { No. of } \\
\text { Fish }\end{array}$ & $\begin{array}{c}\text { No. of } \\
\text { Synapses }\end{array}$ & Synaptic Stain \\
\hline None & 10 & 80 & Heavy \\
iso-OMPA & 2 & 25 & Moderate to heavy \\
DFP & 3 & 31 & None \\
\hline
\end{tabular}
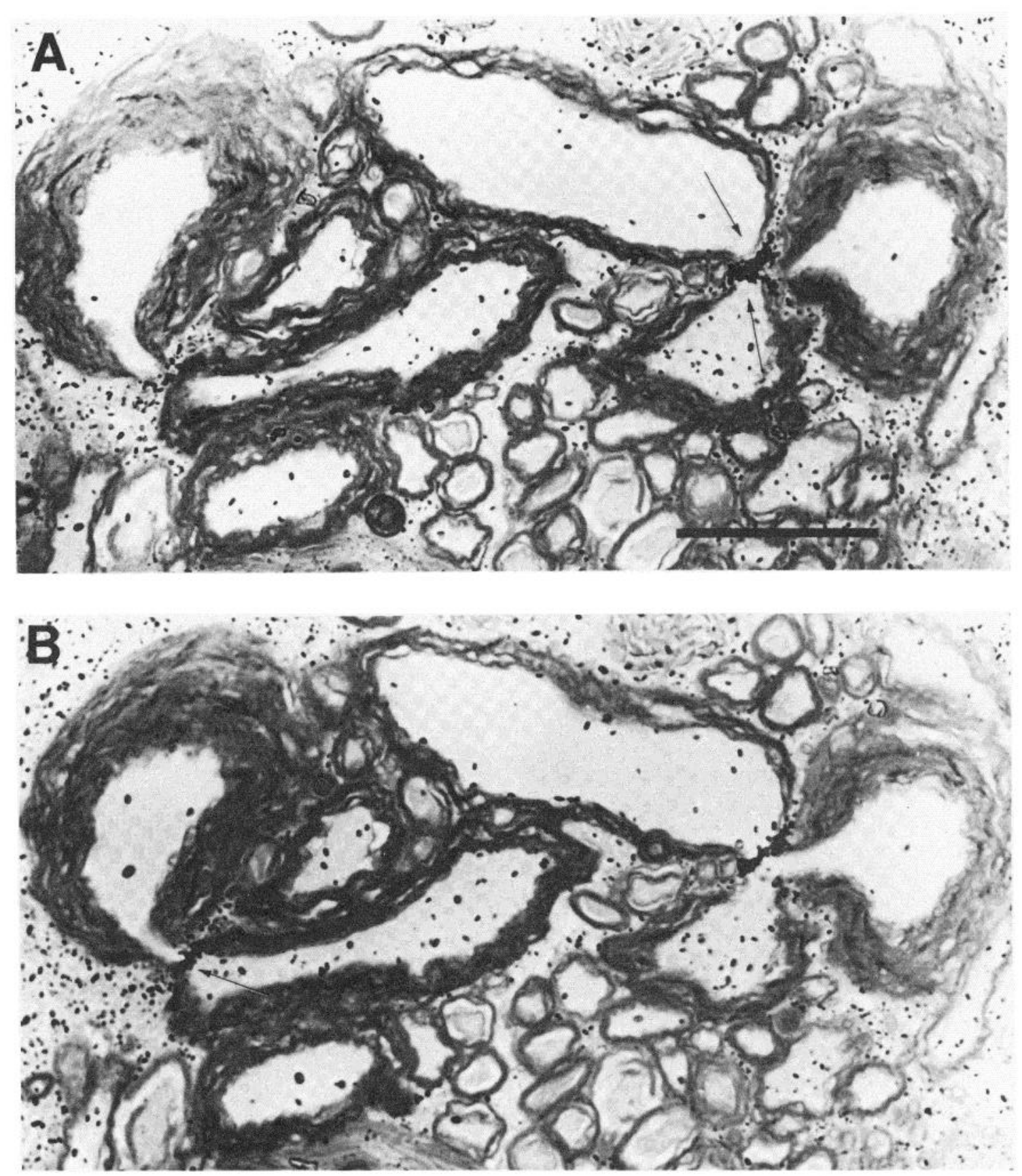

Figure 4. Acetylcholinesterase staining: two adjacent sections from a slice of medulla stained for AChE. $A$, A process from the right Mauthner fiber can be seen to form ipsilateral synapses with each of two different giant fibers (arrows). B, The left Mauthner fiber can be seen to form a cross-process synapse with yet a third giant fiber (arrow). Scale bar, $50 \mu \mathrm{m}$. 
expected of synaptic membrane cut in cross-section (Fig. $2 A$ ). The somewhat scattered distribution might partly be due to tangential sectioning of the synaptic membranes but appears too large to result from this factor alone. For the experiments done with NTB2 emulsion, which is sensitive to gamma radiation, some of the clustering could be due to the greater spread of high energy gamma radiation from the $\left[{ }^{125} \mathrm{I}\right] \alpha-\mathrm{BGT}$ binding site. This effect appears to be of little significance, however, since a similar degree of clustering was seen in experiments with Ilford L4 emulsion (Fig. 3, $A$ to $G$ ), which is insensitive to gamma radiation (M. M. Salpeter, personal communication). The low energy beta emissions of ${ }^{125} \mathrm{I}$ (to which both NTB2 and Ilford L4 emulsions are sensitive) have a half-distance of spread of only $0.1 \mu \mathrm{m}$ (Salpeter et al., 1977) and thus could not cause the observed degree of spread.

Other possible causes of the diffuse distribution of grains might be lack of specificity of $\alpha-\mathrm{BGT}$, the reversal of toxin binding and its subsequent diffusion during the preparative procedures, or the presence of acetylcholine receptors at sites other than the actual synaptic cleft. In regard to the first of these possibilities, the ability of $d$ tubocurarine to block $\alpha$-BGT binding is an indication that the toxin is binding to acetylcholine receptors. The second possibility cannot be ruled out but seems unlikely since in earlier experiments we washed the tissue for very short periods of time (less than $3 \mathrm{~min}$ ) but still saw a similar scattered distribution of grains. The possibility that acetylcholine receptors might be found in sites dislant from the synaplic cleft is supported by the demonstration of $\alpha$-BGT binding sites in presynaptic membrane (Lentz et al., 1976; but see Jones and Salpeter, 1983) and nodes of Ranvier (Freedman and Lentz, 1980). The presence of receptors at such sites in the hatchetfish giant synapse may be the cause of some of the clustering which we see and will be resolved by electron microscopic studies; our current technique provides adequate histological preservation and sufficient labeling so that no major innovations should be necessary for such a study.

Oswald and Freeman (1981) have summarized a large body of data on $\alpha$-BGT binding to neural tissue. They conclude that the binding sites "seem to be located on nicotinic acetylcholine receptors, although $[\alpha-\mathrm{BGT}]$ does not block synaptic transmission at all putative central nervous system nicotinic cholinergic synapses, and its physiological effect has not been extensively tested in the brain." Because toxin binding in the region just ventral to the floor of the fourth ventricle in the hatchetfish medulla is largely restricted to the giant synapses, we may be able to compare binding affinities and physiological effects at an identified central synapse and resolve some of the current concerns about neuronal nicotinic cholinergic synapses.

The AChE staining (Fig. 4) provides ancillary evidence that the Mauthner fiber is indeed cholinergic (and recently we have extended this finding to goldfish (Carassius auratus) and killifish (Fundulus heteroclitus)). The staining was not appreciably reduced by pretreatment with the pseudocholinesterase-blocking drug iso-OMPA but was eliminated by pretreatment with DFP (Fig. $1 B$ ). The presence of acetylcholinesterase suggests that re- moval of ACh from the synaptic cleft involves degradation as well as diffusion. This observation will be significant in analyzing the decay of evoked postsynaptic current and miniature postsynaptic potentials at the giant synapse (Day et al., 1981; Huse and Bennett, 1981).

\section{References}

Auerbach, A. A., and M. V. L. Bennett (1969) Chemically mediated transmission at a giant fiber synapse in the central nervous system of a vertebrate. J. Gen. Physiol., 5.3: 183-210.

Blanchard, S. G., U. Quast, K. Reed, T. Lee, M. I. Schimerlik, R. Vandlen, T. Claudio, C. D. Strader, H. -P. H. Moore, and M. A. Raftery (1979) Interaction of $\left[{ }^{125} I\right]-\alpha$-bungarotoxin with acetylcholine receptor from Torpedo californica. Biochemistry 18: 1875-1883.

Chang, C. C., and C. Y. Lee (1963) Isolation of neurotoxins from the venom of Bungarus multicinctus and their modes of neuromuscular blocking action. Arch. Int. Pharmacodyn. 144: 241-257.

Day, J. W., W. D. Huse, and M. V. L. Bennett (1981) Two phase decay of MPSPs at the hatchetfish giant synapse. Soc. Neurosci. Abstr. 7: 724 .

Faber, D. S., and H. Korn (1978) Neurobiology of the Mauthner Cell, pp. 123-124, Raven Press, New York.

Freedman, S. D., and T. L. Lentz (1980) Binding of horseradishperoxidase $\alpha$-bungarotoxin to axonal membranes at nodes of Ranvier. J. Comp. Neurol. 193: 179-185.

Hall, D. H., J. W. Day, L. M. Hall, and M. V. L. Bennett (1981) $\alpha$-Bungarotoxin labelling of an identified central synapse. Soc. Neurosci. Abstr. 7: 703.

Highstein, S. M., and M. V. L. Bennett (1975) Fatigue and recovery of transmission at the Mauthner fiber-giant fiber synapse of the hatchetfish. Brain Res. 98: 229-242.

Huse, W. D., and M. V. L. Bennett (1981) Postsynaptic currents of the Mauthner fiber-giant fiber synapse in the hatchetfish. Biophys. J. 33: 14a.

Jones, S. W., and M. M. Salpeter (1983) Absence of $\left[{ }^{125} \mathrm{I}\right] \alpha-$ bungarotoxin binding to motor nerve terminals of frog, lizard, and mouse muscle. J. Neurosci. 3: 326-331.

Kalt, M. R., and B. Tandler (1971) A study of fixation of early amphibian embryos for electron microscopy. J. Ultrastruci. Res. 36: 633-645.

Karnovsky, M. J., and L. Roots (1964) A "direct-coloring" thiocholine method for cholinesterases. J. Histochem. Cytochem. 12: 219-221.

Lentz, T. L., J. Chester, and J. Rosenthal (1976) Localization of acetylcholine receptors with peroxidase labeled $\alpha$-bungarotoxin. In 34th Annual Proceedings of the Electron Microscopy Society of America, G. W. Bailey, ed., Claitor's Publishing Division, Baton Rouge.

Lewis, P. R. (1961) The effect of varying the conditions in the Koelle technique. Bibl. Anat. 2: 11-20.

Lewis, P. R., and C. C. D. Shute (1966) The distribution of cholinesterase in cholinergic neurons demonstrated with the electron microscope. J. Cell Sci. 1: 381-390.

Matthews-Bellinger, J., and M. M. Salpeter (1978) Distribution of acetylcholine receptors at frog neuromuscular junctions with a discussion of some physiological implications. J. Physiol. (Lond.) 279: 197-213.

Model, P. G., S. M. Highstein, and M. V. L. Bennett (1975) Depletion of vesicles and fatigue of transmission at a vertebrate central synapse. Brain Res. 98: 209-228.

Oswald, R. E., and J. A. Freeman (1981) $\alpha$-Bungarotoxin binding and central nervous system nicotinic acetylcholine receptors. Neuroscience 6 : 1-14. 
Pfister, C., J. Ritter, H. Wenk, A. Schwartz, and U. Meyer (1973) Enzymhistochemische untersuchungen an den Mauthnerschen zellen von Salmo irideus in der biomorphose. $\mathrm{Z}$. Mikrosk. Anat. Forsch. 87: 128-144.

Salpeter, M. M., and L. Bachman (1972) Autoradiography. In Principles and Techniques of Electron Microscopy: Biological Applications, M. A. Hyatt, ed., Vol. 2, pp. 220-278, Van Nostrand Reinhold Co., New York.

Salpeter, M. M., H. C. Fertuck, and E. E. Salpeter (1977) Resolution in electron microscope autoradiography. III. Iodine-125, the effect of heavy metal staining, and a reassess- ment of critical parameters. J. Cell Biol. 72: 161-173.

Schmidt-Nielsen, B. K., J. I. Gepner, N. N. H. Teng, and L. M. Hall (1977) Characterization of an $\alpha$-bungarotoxin binding component from Drosophila melanogaster. J. Neurochem. 29: 1013-1029.

Silver, A. (1974) Biology of Cholinesterases, pp. 72-73, American Elsevier Publishing Co., Inc., New York.

Spira, M. E., P. G. Model, and M. V. L. Bennett (1970) Cholinergic transmission at a central synapse. J. Cell Biol. 47: 199a200a. 